\title{
Intervention analysis with cointegrated time series: the case of the Hawaii hotel room tax
}

\author{
CARL S. BONHAM and BYRON GANGNES \\ Department of Economics, University of Hawaii at Manoa, 2424 Maile W ay, Room 542, \\ Honolulu, HI 96822, USA
}

Tourism taxes have become an important source of revenue for many tourist destinations in the USA. Among the most widely used is the hotel room tax, levied by 47 states and many localities. Room taxes are touted by proponents as a way to shift the local tax burden to non-residents, while the travel industry claims the levies significantly harm their competitiveness. Previous studies of room tax impacts have relied on ex ante estimates of demand and supply elasticities. In this study, we analyse the effect on hotel revenues of the Hawaii room tax using time series intervention analysis. We specify a time series model of revenue behaviour that captures the long-run cointegrating relationships among revenues and important income and relative price variables, as well as other short-run dynamic influences. We estimate the effect on Hawaii hotel room revenues of the 5\% Hawaii hotel room tax introduced in January 1987. We find no evidence of statistically significant tax impacts.

\section{INTRODUCTION}

Tourism taxes have become an important source of revenue for Hawaii and most other tourist destinations. Among the most lucrative is the hotel room tax. Hawaii's room tax generated $\$ 82$ million of revenue in 1990, making it the third largest source of state revenue after the excise tax and the state income tax (Hawaii Department of Business, Economic Development and Tourism, State of Hawaii Data Book, 1991). The prevalence of hotel room taxes and the rates levied have escalated in recent years, with growing state fiscal responsibilities and increasing reluctance to raise tax burdens on local residents; they are now used by at least 47 of the 50 states and some localities (Mak and Sakai, 1993). In Hawaii, a 5\% hotel room tax (transient accommodations tax) was imposed in January 1987, and was increased by one percentage point in July 1994 to finance a new Honolulu convention centre.
The popular appeal of hotel room taxes is straightforward: they appear to be an effective way to shift a portion of the local tax burden from residents to visitors, without imposing a substantial negative burden on the local tourism industry. In addition to expediency, tax shifting to tourists is justified as an equitable means of assessing visitors for their demands on local infrastructure and public services. The casual observations of economists have tended to support this view. Typical is the statement of Combs and Elledge (1979, p. 203), made without empirical evidence, that the 'demand for lodging in a resort [is] inelastic with respect to price.' so that 'a small ad valorem tax imposed on motel rooms and other forms of temporary lodging would have very little impact on the industry and would generate substantial revenue for the local government.' Not surprisingly, hotel operators are less sanguine, claiming that the levies reduce after-tax profits and drive away tourists to competing travel destinations. (See for example The Honolulu Advertiser, 1993.)

\footnotetext{
${ }^{1}$ Between 1984 and 1990, the national average hotel room tax rate rose from $7 \%$ to nearly $10 \%$, according to similar surveys of major US cities (Mak, 1988; Hiemstra and Ismail, 1990). New York city currently has the highest hotel room tax at $19.25 \%$ plus $\$ 2.00$ on every room priced at \$100 or more. (Mak and Sakai, 1993).
} 
Nearly all existing empirical studies of tourism taxes have attempted to gauge the likely impact of prospective taxes using econometric estimates of supply and demand elasticities. These ex ante estimates have produced conflicting evidence on the impact of hotel taxes on the lodging industry. (See for example Fujii, Khaled and Mak, 1985, 1988; Zuraski and Sanders, 1990; Hiemstra and Ismail, 1990.) In this study, we evaluate ex post the effect of the 1987 Hawaii hotel room tax imposition using time series intervention analysis. ${ }^{2}$ We extend the work of Bonham et al. (1992) who consider a univariate model and find a small, though statistically insignificant, decline in room revenues. By generalizing their approach to a multivariate context, we are able to incorporate the influence of other factors that may have affected the hotel revenues during this time period, such as the emergence of the Japanese real estate bubble, the appreciation of the yen, and slowing growth on the US mainland, potentially permitting the effect of the tax change itself to be better isolated. In addition, we treat long-run and seasonal non-stationarity issues that were not addressed adequately in earlier work.

We estimate a multivariate transfer function model with noise that explains the pre-1987 time path of Hawaii hotel revenues, and we look for evidence that the room tax led to a decline in revenues below the path predicted by our model. We allow for the possibility of cointegrating relationships among room revenues and key macroeconomic variables, an extension of traditional intervention analysis that to our knowledge has not previously appeared in the literature. The resulting model of Hawaii hotel room revenues relates growth in hotel room revenues to growth in Californian and Japanese economic activity, US and Japanese wealth, and movements in US interest rates, and it incorporates errorcorrection terms that capture long-run cointegrating relationships among room revenues, Californian and Japanese activity, and the real yen/dollar exchange rate. We test for an independent effect on revenues of the 1987 hotel room tax and find no evidence of statistically significant tax impacts.

\section{MODELLING HOTEL ROOM REVENUES}

We describe the market for hotel room rentals using a simple partial equilibrium demand and supply model. By identifying factors that influence the demand for and supply of lodging services, we determine variables that should be important in an empirical model of room revenues. Data for some factors that appear in the theoretical specification are not available at the monthly frequency used in the empirical model; in such cases, appropriate proxy variables for these effects are used, or the effect is omitted.

At a minimum, demand for room rentals should depend positively on consumer income and negatively on room rental rates. There are likely also important cross-price effects, reflecting (a) consumer substitution between Hawaiian vacations and vacations in other travel destinations, and (b) substitution (or complementarity) between consumption of lodging and non-lodging items in Hawaii (for example, food, tours, etc.). If utility is weakly separable, we can represent this problem as a two-stage budgeting process. ${ }^{3}$ In the first stage, consumers choose an optimal consumption of 'Hawaiian vacations', $D^{H}$, based on their income, $Y$, overall prices of Hawaiian vacations, $P^{H}$, prices of vacations in other tourism markets, $P^{O}$ and prices of non-tourism consumption, $P$ :

$$
D^{H}=F\left(P^{H}, P^{O}, P, Y\right)
$$

Or, for homogeneous demand,

$$
D^{H}=f\left(\frac{P^{H}}{P}, \frac{P^{O}}{P}, \frac{Y}{P}\right)
$$

Given an overall consumption level for Hawaiian vacations, $D^{H}$, tourists will allocate that demand across hotel room services and non-room expenditures (meals, entertainment, etc.) based on relative prices, $P^{R}$ and $P^{N R}$ respectively:

$$
D^{R}=g\left(\frac{P^{R}}{P^{N R}}, D^{H}\right)
$$

In the first stage, the price of Hawaiian vacations includes prices of room and non-room expenditures, as well as transportation costs to and from the islands. In addition to current income, there may also be a role for "permanent income' or wealth $(A)$ as an additional shift parameter. In particular, the Japanese asset 'bubble' may have played a role in the surge in Japanese travel to the islands in the late 1980s. Acknowledging this possibility, and distinguishing between factors affecting westbound visitors (primarily US mainland tourists, with smaller numbers from Canada, and Europe, etc.), and eastbound visitors (primarily from Japan), we write a reduced-form expression for total room demand:

$$
\begin{aligned}
D^{R}= & D_{W}^{R}\left(\frac{P^{R}}{P^{N R}}, \frac{P^{H}}{P_{W}}, \frac{P_{W}^{O}}{P_{W}}, \frac{Y_{W}}{P_{W}}, \frac{A_{W}}{P_{W}}\right) \\
& +D_{E}^{R}\left(\frac{P^{R}}{P^{N R}}, \frac{P^{H}}{P_{E} / E_{\mathrm{Y} / S}}, \frac{P_{E}^{O}}{P_{E} / E_{\mathrm{Y}} / O}, \frac{Y_{E}}{P_{E}}, \frac{A_{E}}{P_{E}}\right)
\end{aligned}
$$

\footnotetext{
${ }^{2}$ See Box, Jenkins and Reinsel (1994), Chapter 12, for a description of the methodology. An important early application was a study by Box and Tiao (1975) of the effect of air pollution control laws. Recent applications include McPheters, Mann, and Schlagenhauf(1984), who analyse the impact of harsher gun laws on property crime rates, and Fomby and Hayes (1990), who examine the effect of the war on poverty on poor families.

${ }^{3}$ See Philips (1983, p. 71), and, in an international trade setting, Armington (1969). The assumption is made here for expositional simplicity.
} 
where $E_{\mathrm{Y} / S}$ and $E_{\mathrm{Y} / O}$ are exchange rates of the yen with respect to the dollar and currencies relevant for other Japanese travel destinations.

On the supply side, we assume that price is a markup over marginal costs:

$$
P_{\mathrm{S}}^{R}=\operatorname{markup} \cdot M C^{R}=M \cdot H\left(P^{L}, P^{K}, P^{Z}, S^{R}\right)
$$

where $P^{L}, P^{K}$ and $P^{Z}$ are the input prices of labour, capital, and other inputs, $S^{R}$ is the quantity supplied, and $P_{S}^{R}$ is the supply price of rooms, which will differ from the consumer price, $P^{R}$, by $P^{R}=(1+\tau) \cdot P_{S}^{R}$ in the presence of an ad valorem room tax, $\tau$.

We combine the equations for demand and supply to obtain a single reduced-form equilibrium solution for price $\left(P_{S}^{R}\right)$ and quantity $\left(Q^{R}\right)$. We are interested in their product, total room revenue net of taxes, $B_{S}^{R}$ :
One set of relative price measures that is available is exchange rates. Changes in the value of the yen relative to the dollar substantially altered the price competitiveness of Hawaiian vacations for Japanese travellers during this time period. A strengthening yen after 1985 may have been an important factor in the strong growth of Japanese tourism in the islands. Yen/dollar exchange rates are an important explanatory variable in the empirical model.

Real disposable income series are available both for the USA and Japan. Since a disproportionately large number of westbound visitors come from the West Coast, we also consider Californian employment as a measure of regional income growth. ${ }^{4}$ Broad measures of wealth can be computed from flow-of-funds data, but not for the monthly frequency of this analysis. Similarly, it would be nice to have a good Japanese land price measure to capture the effects of

$$
B_{S}^{R}=P_{S}^{R} \cdot Q^{R}=B\left(\frac{P^{R}}{P^{N R}}, \frac{P^{H}}{P_{W}}, \frac{P^{H}}{P_{E} / E_{\mathrm{Y} / S}}, \frac{P_{W}^{O}}{P_{W}}, \frac{P_{E}^{O}}{P_{E} / E_{\mathrm{Y}} / O}, \frac{Y_{W}}{P_{W}}, \frac{Y_{E}}{P_{E}}, \frac{A_{W}}{P_{W}}, \frac{A_{E}}{P_{E}}, P_{L}, P_{K}, P_{Z}, M, \tau\right)
$$

Given specific functional forms for supply and demand equations, one could estimate a structural supply-demand model, solve explicitly for revenues, and conduct comparative static exercises to evaluate the impact of a change in hotel room taxes, $\tau$. (For a general comparative static analysis see Fujii, Im and Sakai, 1993.) In this paper, we model hotel room revenues directly. One advantage of this approach is that it allows us to work with a relatively precise measure of our dependent variable. Tax base data allow us to study the revenues of nearly the entire population of hotels, condominiums, bed and breakfast inns, and other short-term accommodations, rather than survey samples of hotel price and quantity. Equation 6 is used to suggest variables relevant for our reduced-form empirical model, without concern for the precise functional form.

Data for many of the variables in Equation 6 can be obtained, or an appropriate proxy variable can be found. Unfortunately, data for most of the key relative prices are not available at the monthly frequency needed for our analysis. In particular, monthly data series are no longer available for Hawaiian consumer prices or their components, preventing us from computing CPI-based proxies for the relative price of room to non-room expenditures or of Hawaiian vacations relative to other destinations. We are unaware of other readily available high-frequency travelindustry data on vacation prices that might be used instead. land appreciation during the 'bubble'. These data are also unavailable at monthly frequencies. ${ }^{5}$ Instead, as a proxy for wealth effects we use stock price indexes for the two countries. Overall consumer price indexes for the USA and Japan are used to deflate nominal stock prices.

Labour and capital costs that may affect hotel room supply are captured by a hotel industry wage rate and time series of long-term US and Japanese interest rates. We have not been able to acquire high-frequency data for local land prices, a third important input price. Note that exchange rates and asset price variables may also influence the cost of capital flowing from Japan to Hawaii.

\section{AN EMPIRICAL MODEL OF HAWAII HOTEL ROOM REVENUES}

We model room revenues using a multiple-input transfer function-noise model, augmented to include long-run cointegrating relationships among a subset of variables. In this section we describe the data, the results of stationarity tests, and adjustment for non-stationarity at seasonal frequencies. We then discuss estimation of cointegrating relationships among key variables, outline the specification of the transfer function model and discuss characteristics of the selected revenue model.

\footnotetext{
${ }^{4}$ Visitors from Japan represented 26\% of total visitors to Hawaii in 1992. The percentage of visitors from California was 21 (See Hawaii Visitors Bureau, 1993.)

${ }^{5}$ Appraisal-based land value data are available at the end of the fiscal year (31 March) and the half fiscal year (30 September), only. Stone and Ziemba (1993) review evidence that Japanese stock and land prices are more closely related than for other countries, although they may not be cointegrated.
} 


\section{Data characteristics and seasonal filtering}

Our data set consists of ten monthly time series - real hotel room revenues $(H R)$, real disposable income in Japan and the US (JPY and USY), Californian non-farm employment $(C A E M P)$, real Japanese and US stock prices $(J P W$ and $U S W)$, the real yen/dollar exchange rate $(E X C H)$, real government bond rates in Japan and the US (JPR and USR), and wages in the Hawaiian hotel industry (HWAGE). (See the Appendix for details.) Because the hotel revenue series is not available prior to 1978 , our sample size is limited to monthly data beginning in 1978:5 and extending to 1990:1. (Lagged data extending back prior to 1978:5 are used for input series.) Natural logarithms of each time series are used.

Casual examination of the data reveals two properties common to many macroeconomic time series: (1) distinct trends, and (2) pronounced seasonality. The seasonal and trend behaviour may be deterministic or stochastic, with the stochastics generated by either stationary or non-stationary processes. Because standard procedures for estimation and inference require stationary regressors, we have evaluated the stochastic properties of each of our data series. ${ }^{6}$

We test for non-stationarity using a method developed in Beaulieu and Miron (1993). This procedure is a straightforward extension of the well known Dickey-Fuller test for zero frequency unit roots and allows us to test the null hypothesis of a unit root at the zero and/or seasonal frequencies based on a single OLS regression. ${ }^{8}$ We estimate the following regression,

$$
\begin{aligned}
y_{13, t}= & \sum_{k=1}^{12} \gamma_{k} y_{k, t^{-1}}+\sum_{k=2}^{12} m_{k} S_{k t}+\sum_{j=1}^{p} \varphi_{j} y_{13, t^{-}} \\
& +m_{0} D T_{t}+m_{1}+\varepsilon_{t}
\end{aligned}
$$

where $y_{13, t}=\left(1-B^{12}\right) x_{t}$ is the $x_{t}$ series filtered to remove all possible unit roots, and each of the $y_{k, t^{-}}, k=1, \ldots, 12$, are filtered to remove all but one of the 12 possible seasonal and long-run unit roots. ${ }^{9}$ For instance, $y_{1, t^{-1}}=S(B) x_{t^{-1}}$ is filtered to remove all seasonal roots but not the zero frequency root, while $y_{2, t^{-1}}$ is $x_{t^{-}}$filtered to remove the zero frequency and all seasonal unit roots except for the root at frequency $\omega=1 / 2$ of a $(2 \pi)$ cycle. Finding a unit root in $x_{t}$ at $\omega=0$ implies accepting the null hypothesis that $\gamma_{1}$ is zero, that is that the series is integrated at the long-run frequency. When $\gamma_{2}$ is zero, we cannot reject the null of a unit root at the frequency $\omega=1 / 2$, a bimonthly cycle. The remaining seasonal roots are complex conjugates; finding a pair of complex unit roots requires that both coefficients $\gamma_{k}$ and $\gamma_{k-1}$ equal zero for $k=4,6,8,10,12$. Tests are based on $t$-statistics for $\gamma_{1}$, and $\gamma_{2}$, and $F$-statistics for joint tests of the complex pairs. ${ }^{10}$

In Equation 7, $S_{k, t}$ for $k=2, \ldots, 12$ are seasonal dummies included to capture possible deterministic seasonality. A constant term, $m_{1}$, and a deterministic trend, $D T_{t}$, are also included. Lags of the dependent variable $Y_{13, t-j}$ are added to whiten the residuals $\varepsilon_{t}$, with the number of lags, $p$, determined empirically. ${ }^{11}$ The power of our unit root tests is reduced if we augment Equation 7 with too many auxiliary parameters, $\varphi_{j}$, to reduce the residuals to white noise or, $m_{k}$, to model all possible deterministic components. However, if we exclude auxiliary parameters that belong in the data generating process, the size of the tests may be much greater than the chosen significance level, and the test will have low power against certain alternative data generating processes (DGP). (See Ghysels, Lee and Noh, 1994.)

Results of unit root tests are presented in Table 1. All series are found to be $I_{0}(1)$, and many of them are found to have seasonal unit roots as well. The most common seasonal unit root is at frequency $\omega=1 / 3$, a quarterly cycle. Where seasonal unit roots are detected, this information is used to filter out the stochastic non-stationary seasonal component of the series so that we can obtain consistent estimates of any long-run cointegrating relationships that may exist. ${ }^{12}$ The filters applied to remove the detected seasonal unit roots are indicated in the last column of Table 1.

\footnotetext{
${ }^{6}$ The existence of stochastic trend and seasonal components in time series has received considerable attention in the econometrics literature over the past decade. See Campbell and Perron (1991) for a recent survey of issues related to long-run (non-seasonal) unit roots and cointegration. For seasonality, see Hylleberg (1992).

${ }^{7}$ Their test extends, to the case of monthly data, the test for quarterly time series developed in Hylleberg, Engle, Granger and Yoo (1990) (hereafter HEGY). HEGY define an integrated series as one that has an infinite value in its spectrum at a given frequency $\omega$. For monthly data, the frequencies of interest correspond to $\omega=i / 12, i=0, \ldots, 11$, of a $(2 \Pi)$ cycle. A series $(1-B) x_{t}=e_{t}$ that is integrated of order 1 at frequency $\omega=0$, is denoted $I_{0}(1)$. More generally, a series integrated of order $d$ at frequency $\omega$ is denoted $I_{\omega}(d)$.

${ }^{8}$ Ghysels, Lee and Noh (1994) provide a detailed discussion of practical issues relevant to testing for unit roots in seasonal processes using the HEGY test, a test due to Dickey, Hasza and Fuller (1984), and the standard Dickey-Fuller test. Hylleberg (1993) compares the HEGY test with a test developed by Canova and Hansen (1993).

${ }^{9} B$ is the back-shift operator, $B^{n} x_{t}=x_{t^{-}}$.

${ }^{10}$ See Beaulieu and Miron (1993) for definitions of $y_{k}$, and a more complete description of the testing procedure.

${ }^{11}$ Following Campbell and Perron (1991), we begin with a general specification, with $p$ set at a large value, $p=p_{\max }=24$. We then reduce the lag length until a statistically significant coefficient, $\hat{\varphi}_{j}$, is found at the $5 \%$ level.

${ }^{12}$ Seasonality of macroeconomic time series is often dealt with by using seasonal adjustment filters such as the Census X-11 procedure. We have purposely avoided the use of such symmetric filters here because their use of leads as well as lags may cause misidentification of the tax intervention. However, seasonal unit roots must be removed from the data to ensure consistent estimation of zero frequency cointegrating vectors. (See Engle, Granger and Hallman, 1989; HEGY, 1990.)
} 
Table 1. Results of unit root tests and seasonal adjustments applied

\begin{tabular}{|c|c|c|c|c|}
\hline Series & Mnemonic & $\begin{array}{l}\text { Zero frequency } \\
\text { unit root }\end{array}$ & $\begin{array}{l}\text { Frequency of } \\
\text { seasonal } \\
\text { unit } \operatorname{root}(\mathrm{s})\end{array}$ & Seasonal filter \\
\hline Hotel room revenues & $H R$ & Yes & $1 / 3$ & $1+B+B^{2}$ \\
\hline Real $¥ / \$$ exchange rate & $E X C H$ & Yes & None & None \\
\hline US real disposable income & $U S Y$ & Yes & $1 / 2$ & $1+B$ \\
\hline Japanese real disposable income & $J P Y$ & Yes & $1 / 2,1 / 3$ & $1+2 B+2 B^{2}+B^{3}$ \\
\hline Californian employment & $C A E M P$ & Yes & $1 / 3$ & $1+B+B^{2}$ \\
\hline US real wealth & $U S W$ & Yes & None & None \\
\hline Japanese real wealth & $J P W$ & Yes & $1 / 3$ & $1+B+B^{2}$ \\
\hline US real interest rate & $U S R$ & Yes & None & None \\
\hline Japanese real interest rate & $J P R$ & Yes & $1 / 3$ & $1+B+B^{2}$ \\
\hline Hawaii real hotel wage & $H W A G E$ & Yes & $1 / 4$ & $1+B^{2}$ \\
\hline
\end{tabular}

Notes: Except for interest rates, natural logarithms of all series are used. All underlying data series are non-seasonally adjusted, except for US disposable income. The seasonal filters are expressed as polynomials in the backshift (lag) operator, $B$, where $B_{X_{\mathrm{t}}}^{i}=X_{t^{-} i}$. Details available from the authors upon request.

\section{Identifying long-run determinants of hotel room revenues}

Since we find zero frequency unit roots in each of the time series, we would like to test for cointegration among the complete set of data series. Given our small sample and the potentially large number of lags that would be needed to whiten residuals in a vector error-correction model with monthly data, we choose to test for cointegration among only a subset of variables. Specifically, we focus on the series which we believe a priori to have the closest relationship to hotel room revenues in Hawaii: real Japanese disposable income, Californian income (proxied by employment), and the real yen/dollar exchange rate (all series in logarithms). ${ }^{13}$

To test for cointegration among these four variables, we use a procedure developed in Johansen (1988) and applied in Johansen and Juselius (1990). The data generating process for the four-element vector process $\boldsymbol{x}_{t}=[H R, C A E M P, J P Y, E X C H]^{\prime}$ can be written as an unrestricted vector autoregression in levels:

$$
\begin{gathered}
\boldsymbol{x}_{t}=\pi_{1} \boldsymbol{x}_{t-1}+\pi_{2} \boldsymbol{x}_{t-2}+\cdots+\pi_{k} \boldsymbol{x}_{t-k}+\varepsilon_{t}, \\
\varepsilon_{t} \sim \operatorname{NID}(0, \Sigma)
\end{gathered}
$$

where $\pi_{i}$ are $(4 \times 4)$ matrices of parameters for all lags $i=1, \ldots, k=p-1$. This system can be reparameterized as the vector error-correction model ${ }^{14}$

$$
\begin{aligned}
\Delta \boldsymbol{x}_{t}= & \Gamma_{1} \Delta \boldsymbol{x}_{t-1}+\Gamma_{2} \Delta \boldsymbol{x}_{t-2}+\cdots+\Gamma_{k-1} \Delta \boldsymbol{x}_{t-k+1} \\
& +\prod \boldsymbol{x}_{t-1}+\varepsilon_{t}
\end{aligned}
$$

where $\Gamma_{i}=-\left[\pi_{i+1}+\pi_{i+2}+\cdots+\pi_{k}\right], i=1, \ldots, k-1$, and $\Pi=-\left[I_{n}-\pi_{1}-\pi_{2}-\cdots-\pi_{k}\right]$. The only difference between Equation 9 and a standard VAR in differences is the error-correction term, $\Pi \boldsymbol{x}_{t^{-}} k$. It is this term which contains information about the long-run cointegrating relationships among the four variables in $\boldsymbol{x}_{t}$. Since $\boldsymbol{x}_{t}$ is a vector of $I_{0}(1)$ variables, $\Delta \boldsymbol{x}_{t}$ is $I_{0}(0)$. Therefore, the dependent variable in Equation 9 and the first $k-1$ regressors are all stationary processes. If the final term, $\Pi \boldsymbol{x}_{t^{-1}}$, is to be stationary, then $\Pi$ must either be the null matrix or it must contain up to three cointegrating vectors which form stationary linear combinations of the variables in $\boldsymbol{x}_{t}{ }^{15}$

Johansen and Juselius (1990) develop two types of eigenvalue tests for determining the number of cointegrating vectors. The trace test is a test of the hypothesis that there are at most $r$ cointegrating vectors against the alternative of

\footnotetext{
${ }^{13}$ It is also possible that a subset of time series is cointegrated at seasonal frequencies. (See Engle, Granger, Hylleberg and Lee, 1993.) Of the four time series considered here, real hotel room revenues, real Japanese disposable income, and Californian employment have a unit root at the same seasonal frequency, $\omega=1 / 3$. (Real Japanese disposable income also has unit root at $\omega=1 / 2$.) Tests for seasonal cointegration in the VAR framework used here are possible, but would involve estimating additional coefficients (those on the series filtered to remove all but the root at $\omega=1 / 3$ ), leaving even fewer degrees of freedom. Also, there are no published critical values for seasonal cointegration tests with monthly data. We have chosen to leave the issue of seasonal cointegration for future work that can exploit the full sample of data.

${ }^{14}$ See for example Hamilton (1994), Chapter 19.

${ }^{15}$ The number of cointegrating vectors is determined by the rank of $\Pi, r(\Pi)$. If no stationary linear combinations of the four variables exist, $r(\Pi)$ is zero. Generally, if $0<r(\Pi)<4$, there will be some $(4 \times r)$ matrices $\alpha$ and $\beta$, such that $\Pi=\alpha \beta^{\prime}$, and $\beta^{\prime} x_{t^{-}} 1$ is stationary. The rows of $\beta^{\prime}$ are cointegrating vectors describing long-run equilibrium relationships. (The $4 \times r$ matrix $\alpha$ gives vector error-correction terms that determine the rate at which the system approaches its long-run equilibrium.)
} 
Table 2. Cointegration tests

\begin{tabular}{lccccc}
\hline$\Delta \boldsymbol{x}_{t}=\Gamma_{1} \Delta \boldsymbol{x}_{t-1}+\Gamma_{2} \Delta \boldsymbol{x}_{t-2}+\cdots+$ & $\Gamma_{k-1} \Delta \boldsymbol{x}_{t-k+1}+\Pi \boldsymbol{x}_{t-1}+\varepsilon_{t}$ \\
\hline & Trace test & & \multicolumn{3}{c}{ Maximum eigenvalue test } \\
\hline$r=0$ & $r \leqslant 1$ & $r \leqslant 2$ & $r=0$ & $r=1$ & $r=2$ \\
$68.67^{*}$ & $29.62^{*}$ & 10.40 & $39.05^{*}$ & 19.22 & 9.99 \\
\hline
\end{tabular}

Note: $r$ is the number of cointegrating vectors, i.e. the rank of the matrix $\Pi$ in Equation 9.

* Indicates statistical significance at the 5\% level. Critical values for the cointegration tests are taken from Osterwald-Lenum(1992, Table A1).

no cointegration. The maximum eigenvalue test is used to test the null of $r$ cointegrating vectors against the alternative of $r-1$ cointegrating vectors. Following these procedures, we test for cointegration among the four series of real hotel room revenues, Japanese real disposable income, Californian employment, and the real yen/dollar exchange rate. Results are given in Table 2. Using the trace test, we reject the null of no cointegrating vectors, as well as the null of one or fewer cointegrating vectors. Finally we cannot reject at the $5 \%$ level the null of two cointegrating vectors. Results from the maximum eigenvalue test indicate one fewer cointegrating vector. While we reject the null of zero cointegrating vectors in favour of the alternative $r=1$, we cannot reject the null that $r=1$ in favour of $r=2$. Therefore the maximum eigenvalue test suggests that only one cointegrating vector exists, while the trace test indicates that there are two.

The cointegrating vectors (eigenvectors) associated with the two largest eigenvalues, normalized on the hotel revenue series, are:

$$
\begin{aligned}
H R_{t}= & 1.437 \cdot C A E M P_{t}+1.142 \cdot J P Y_{t} \\
& -0.882 \cdot E X C H_{t}+z_{1, t} \\
H R_{t}= & -1.313 \cdot C A E M P_{t}+2.474 \cdot J P Y_{t} \\
& -0.615 \cdot E X C H_{t}+z_{2, t}
\end{aligned}
$$

The cointegrating relationships imply substantial effects on hotel room revenues of both income and real exchange rates. In the first vector, for example, a $1 \%$ increase in Californian employment increases hotel room revenues over $1.4 \%$, if other factors are unchanged, while a $1 \%$ appreciation of the dollar leads to a $0.9 \%$ decline in room revenues. (All coefficients are significantly different from zero at the $5 \%$ level.)

If actual hotel revenues deviate from the long-run equilibrium level implied by Equation 10 or 11, the equilibrium errors $z_{1, t}$ and $z_{2, t}$ will be non-zero, and $H R_{t}$ will adjust toward the long-run equilibrium. The errors $z_{1, t}$ and $z_{2, t}$ are introduced as inputs in the general transfer function/noise model of room revenues developed below. The speed of adjustment of room revenues to the long-run path is then estimated within the full dynamic model.

\section{A multiple-input transfer function/noise model of hotel room revenues}

In this section we develop a dynamic model of hotel room revenues using the transfer function approach developed by Box and Jenkins (Box, Jenkins and Reinsel, 1994). We extend the Box-Jenkins methodology to incorporate longrun cointegrating relationships, an extension that apparently has not previously appeared in the literature.

Following the approach of Box and Jenkins, we assume the real revenue series (in logarithms) is generated by a multiple-input transfer function model with noise,

$$
H R_{t}=\sum_{j=1}^{m} v_{j}(B) x_{j, t-b}+\eta_{t}
$$

where $v_{j}(B)=v_{j 0}+v_{j 1} B+v_{j 2} B^{2}+\cdots+v_{j k_{j}} B^{k}, j=1, \ldots, m$, are transfer functions that relate exogenous input variables $x_{j, t}$ to the output series $H R_{t}$ and $b_{j}$ is a pure delay parameter indicating the number of periods before a change in $x_{j, t}$ begins to affect $H R_{t}$. The dynamic processes described by these transfer functions can be more parsimoniously represented by ratios of moving average and autoregressive polynomials in the backshift operator, $w_{j}(B)$ and $\delta_{j}(B)$,

$$
\begin{aligned}
& \qquad v_{j}(B)=\frac{w_{j 0}+w_{j 1} B+w_{j 2} B^{2}+\cdots+w_{j s} B^{s}}{1-\delta_{j 1} B-\delta_{j 2} B^{2}-\cdots-\delta_{j r} B^{r}}=\frac{w_{j}(B)}{\delta_{j}(B)}, \\
& \text { for } j=1, \ldots, m
\end{aligned}
$$

The unexplained noise process $\eta_{t}$ can similarly be modelled as $\eta_{t}=\frac{\theta(B)}{\phi(B)} a_{t}$, where $a_{t}$ is a white noise process. The transfer function model with noise (12) can then be rewritten as:

$$
H R_{t}=\sum_{j=1}^{m} \frac{w_{j}(B)}{\delta_{j}(B)} x_{j, t-b}+\frac{\theta(B)}{\phi(B)} a_{t}
$$

The attraction of the transfer function approach is that it provides a parsimonious representation of the real revenue series in terms of its own past and a small set of plausible leading indicator inputs. ${ }^{16}$

Standard practice involves differencing the output and input series to ensure stationarity. While we follow this

\footnotetext{
${ }^{16}$ An alternative approach would be to follow a general-to-specific, two-step error-correction modelling procedure and specify an autoregressive distributed lag (ADL) model (or autoregressive/moving average model with exogenous variables - ARMAX) with error-correction terms. See Harvey (1990), Chapters 7 and 8. We chose the transfer function approach because of the natural extension to modelling the intervention effect of a tax change.
} 
practice for most variables, we also incorporate the long-run cointegrating relationships identified earlier. This gives the model,

$$
\begin{aligned}
\Delta H R_{t}= & \alpha_{1} z_{1, t-1}+\alpha_{2} z_{2, t-1}+\sum_{j=1}^{m} \frac{w_{j}(B)}{\delta_{j}(B)} \Delta x_{j, t-b} \\
& +\frac{\theta(B)}{\phi(B)} a_{t}
\end{aligned}
$$

The equilibrium errors $z_{1, t^{-1}}$ and $z_{2, t^{-1}}$ are as defined in Equations 10 and 11. The error-correction coefficients $\alpha_{1}$ and $\alpha_{2}$ are expected to have negative signs, so that deviations from the cointegrating relationship are eliminated over time. ${ }^{17}$ This specification permits us to impose the long-run cointegrating relationships among hotel room revenues, economic activity, and exchange rate variables, while also capturing, through standard transfer function terms, the short-run influence on room revenues of all the input variables.

The Box-Jenkins approach to transfer function modelling is very similar to their approach to modelling univariate time series and involves a particular strategy of identification, estimation, and diagnostic testing. The identification stage may be thought of as a three-step process. First we obtain rough estimates of a finite number of impulse response weights, $v_{j 0}, v_{j 1}, \ldots, v_{j k}$, for $j=1, \ldots, m$ from the autoregressive distributed lag representation in Equation 12. These are used to get some idea about the shape of the model's dynamic structure. Second, on the basis of the estimated lag structure, we choose orders for the moving average and autoregressive polynomials, $r$ and $s$, so that the rational polynomials in Equation 13 provide an adequate approximation to the transfer functions $v_{j}(B)$. Finally, we identify a suitable $\operatorname{ARMA}(p, q)$ process for the disturbance term $\eta_{t}$.

Estimation of the transfer function impulse lag coefficients creates several problems in the multi-input model that do not arise in the single-input case. First, the number of lags to estimate must be chosen judiciously to avoid depleting degrees of freedom. For instance, in our case with eight inputs and 12 lags of each variable, the number of parameters to estimate would exceed the sample size. Second, we expect at least some degree of multicollinearity due to autocorrelation and cross correlation among the $x_{j}$ variables. This multicollinearity will reduce the precision of parameter estimates and may lead us to exclude variables because they incorrectly appear to be statistically insignificant. Finally, as in the case of the single-input transfer function model, the residuals, $\eta_{t}$, will generally be serially correlated, resulting in biased standard errors and inefficient estimates from OLS regressions.

We address each of these problems by following a procedure suggested in Edlund (1984). ${ }^{18}$ Initial lag lengths for the input variables are set fairly conservatively, and insignificant lags are eliminated. We begin with a maximum of eight lags for $C A E M P, J P Y, E X C H, U S Y$ and the wealth variables ( $U S W$ and $J P W$ ), and a maximum lag of six months for hotel wages $(H W A G E)$. Six lags each of US and Japanese interest rates $(U S R$ and $J P R)$ are included, but with a 12-month pure delay reflecting our expectation that monetary influences act with a considerable lag. The actual lag lengths used in identifying the orders for the six $A R$ and $M A$ polynomials are chosen empirically through a series of tests of the predictive power of the estimated lag coefficients. We use biased regression (ridge) techniques to reduce the effect of multicollinearity on the variance of our estimated lag coefficients. We test for serially correlated residuals, $\eta_{t}$, and correct for any serial correlation before conducting inference. ${ }^{19}$

Using this general-to-specific testing procedure, we were able to reduce the parameterization of the system to the final model reported in Table $3 .^{20}$ This model constitutes our pre-intervention model of hotel room revenues. The model contains five inputs (growth rates of Californian employment, real Japanese disposable income, real US and Japanese stock price series, and the real US seven-year government bond rate), as well as the two error-correction terms. Although the change in the real yen/dollar exchange rate does not show up as a separate input (it did not have any explanatory power), it does enter the model in levels via the error-correction terms.

The adequacy of the pre-intervention model is crucial, since it serves as a reference point for evaluating the effects of room taxes on revenues. The model fits the data very well; $76 \%$ of the variation in the growth of real room revenues is captured by the inputs plus noise. The Ljung-Box $Q$-statistic, for the null hypothesis that the first 25 residual autocorrelations are jointly equal to zero, has a marginal significance level of over $33 \%$. Thus, the unexplained movements in real hotel revenue growth are not systematic. Fig. 1 illustrates both the in- and out-of-sample performance of the pre-intervention model. ${ }^{21}$ The post-intervention

\footnotetext{
${ }^{17}$ Notice that Equation 15 is essentially the first row of the VECM, Equation 9, augmented with distributed lags on additional exogenous explanatory variables.

${ }^{18}$ This method differs from Box and Jenkins who recommend pre-whitening the time series before estimating cross-correlationfunctions used in obtaining estimates of $\hat{v}_{j}$.

${ }^{19}$ We use Ljung-Box (1978) $Q$-statistics to test for serial correlation, and Hannan (1963) efficient estimation (a frequency domain version of generalized least squares) to correct for serial correlation when estimating the impulse response weights.

${ }^{20}$ The identified model (Equation 15) is estimated by non-linear least squares, using the RATS v. 4.02 Boxjenk command.

${ }^{21}$ The in-sample forecasts are static forecasts: actual values minus the residuals from Equation 15 estimated over the pre-intervention sample period 1978:9 to 1986:12. The out-of-sample forecasts for 1987:1 to 1990:1 are dynamic forecasts; predicted revenue growth rates are fed forward as lagged inputs to successive periods' revenue growth forecasts (In Fig. 1, the dashed lines shows forecast values, the solid line, actual data.).
} 
Table 3. Transfer function parameter estimates for the pre-intervention sample, 1978:9-1986:12

\begin{tabular}{|c|c|c|c|}
\hline & $\begin{array}{l}\text { Input } \\
\text { variable }\end{array}$ & Estimate & $\begin{array}{l}\text { Marginal } \\
\text { significance } \\
\text { level }\end{array}$ \\
\hline $\begin{array}{l}z_{1, t^{-}} \\
z_{2, t^{-}}\end{array}$ & $\begin{array}{l}\alpha_{1} \\
\alpha_{2}\end{array}$ & $\begin{array}{r}0.0699 \\
-0.2024\end{array}$ & $\begin{array}{l}0.0000 \\
0.0000\end{array}$ \\
\hline$C A E M P_{t}$ & $\begin{array}{l}\mathrm{W}_{1,1} \\
\mathrm{~W}_{1,2} \\
\mathrm{~W}_{1,3}\end{array}$ & $\begin{array}{r}-7.3992 \\
-6.6624 \\
9.9593\end{array}$ & $\begin{array}{l}0.0921 \\
0.2918 \\
0.0189\end{array}$ \\
\hline$J P Y_{t}$ & $\begin{array}{l}\mathrm{W}_{2,1} \\
\mathrm{~W}_{2,2}\end{array}$ & $\begin{array}{l}-0.0533 \\
-0.3945\end{array}$ & $\begin{array}{l}0.4065 \\
0.0000\end{array}$ \\
\hline$U S W_{t}$ & $\mathrm{w}_{3,1}$ & -0.0006 & 0.0610 \\
\hline$J P W_{t}$ & $\begin{array}{l}\mathrm{W}_{4,3} \\
\mathrm{~W}_{4,4} \\
\mathrm{~W}_{4,5}\end{array}$ & $\begin{array}{l}0.0009 \\
0.0004 \\
0.0005\end{array}$ & $\begin{array}{l}0.0089 \\
0.1780 \\
0.1940\end{array}$ \\
\hline$U S R_{t}$ & $\begin{array}{l}\mathrm{W}_{5,15} \\
\mathrm{~W}_{5,16} \\
\mathrm{~W}_{5,17}\end{array}$ & $\begin{array}{l}-0.0076 \\
-0.0012 \\
-0.0158\end{array}$ & $\begin{array}{l}0.1823 \\
0.8328 \\
0.0088\end{array}$ \\
\hline $\bar{R}^{2}$ & $\begin{array}{l}\theta_{2} \\
\phi_{3} \\
\phi_{9}\end{array}$ & $\begin{array}{r}0.3991 \\
-0.9331 \\
0.3275 \\
0.7583\end{array}$ & $\begin{array}{l}0.0004 \\
0.0000 \\
0.0001\end{array}$ \\
\hline $\operatorname{MSLQ}(25)$ & & 0.3387 & \\
\hline
\end{tabular}

Note: $\bar{R}^{2}$ is the correlation coefficient adjusted for degrees of freedom, MSLQ(25) is the marginal significance of the Ljung-Box $Q$-statistic for the test of the null hypothesis that the first 25 autocorrelations are jointly equal to zero. All variables are as defined in the text and are in differenced logarithms, except for the two equilibrium error terms, $z_{1, t^{-1}}$ and $z_{2, t^{-1}}$.

forecasts have a root mean squared error of 0.246 and clearly track the growth rates quite closely. On the basis of these results, we would not expect the imposition of a hotel room tax in 1987:1 to have significantly affected the growth of real hotel room revenues in Hawaii.

Interpretation of the transfer functions for individual inputs is complicated by the fact that some of the observed dynamic behaviour is due to stationary seasonality, and because economic theory has little to say about short-run dynamics. In some cases the signs of these terms can be given meaningful economic interpretation; in others the direction of effects seems counter-intuitive. For instance, the transfer function for Japanese real wealth implies a small net rise in room revenues when Japanese wealth increases (the impulse response is given by $0.0009+0.0004 B+0.0005 B^{2}$, with a three-period pure delay). On the other hand, the transfer function for real growth in Japanese disposable income, $-0.053 B-0.395 B^{2}$, implies a counter-intuitive negative relationship, as does the transfer function for Californian employment $\left(-7.40 B-6.7 B^{2}+9.96 B^{3}\right)$. In the latter case only the positive impulse response weight at lag three is significantly different from zero at the $5 \%$ level. $^{22,23}$

The transfer function terms reflect only the short-run influences on room revenues of the input variables around the long-run equilibrium path described by the cointegrating relationships defined by $z_{1, t^{-1}}$ and $z_{2, t^{-1}}$. The first equilibrium error has a counter-intuitive positive coefficient of $\alpha_{1}=0.07$, while the second term has a coefficient of $\alpha_{2}=-0.20$. These loading coefficients measure the speed of adjustment of real room revenues to a disequilibrium error. For example, the second loading coefficient by itself suggests that short-run changes in room revenues, perhaps due to a temporary fall in Japanese income, would push room revenues back toward their long-run path, with $20 \%$ of the equilibrium gap eliminated in the first month. In this way, deviations of real hotel room revenues from their long-run expected values alter the growth rate of revenues until equilibrium is restored several months later.

\section{THE EFFECT OF THE HOTEL ROOM TAX - AN INTERVENTION ANALYSIS}

Considering the fit of the out-of-sample forecast shown in Fig. 1, we expect the pre-intervention model to hold up well when estimated over the full sample. This expectation is confirmed by the full-sample estimation results shown in Table 4. All of the full-sample parameter estimates are within one and a half standard errors (most are within one standard error) of those reported in Table 3 for the preintervention sample. The moving average coefficients on the growth in Californian employment (lag two) and the change in the US real government bond rate (lag 16) reverse signs; however neither of these parameters is (individually) significantly different from zero in either sample. The model

\footnotetext{
${ }^{22}$ Inspection of the data suggests that the short-run relationships may be the result of an inverse seasonal relationship among series. While we have filtered out non-stationary seasonality (seasonal unit roots), stationary seasonal effects remain and are modelled by the transfer functions and the error model.

${ }^{23}$ In the identified model, only the noise term enters as a ratio of $M A$ and $A R$ polynomials, so that in effect we have identified what is known as an ARMAX model - an $A R M A$ model with added explanatory variables. This specification resulted from the empirical tests on our initial transfer function specification, and the requirement that the individual transfer functions meet stability conditions. (See Box, Jenkins and Reinsel, 1994, p. 376.)
} 


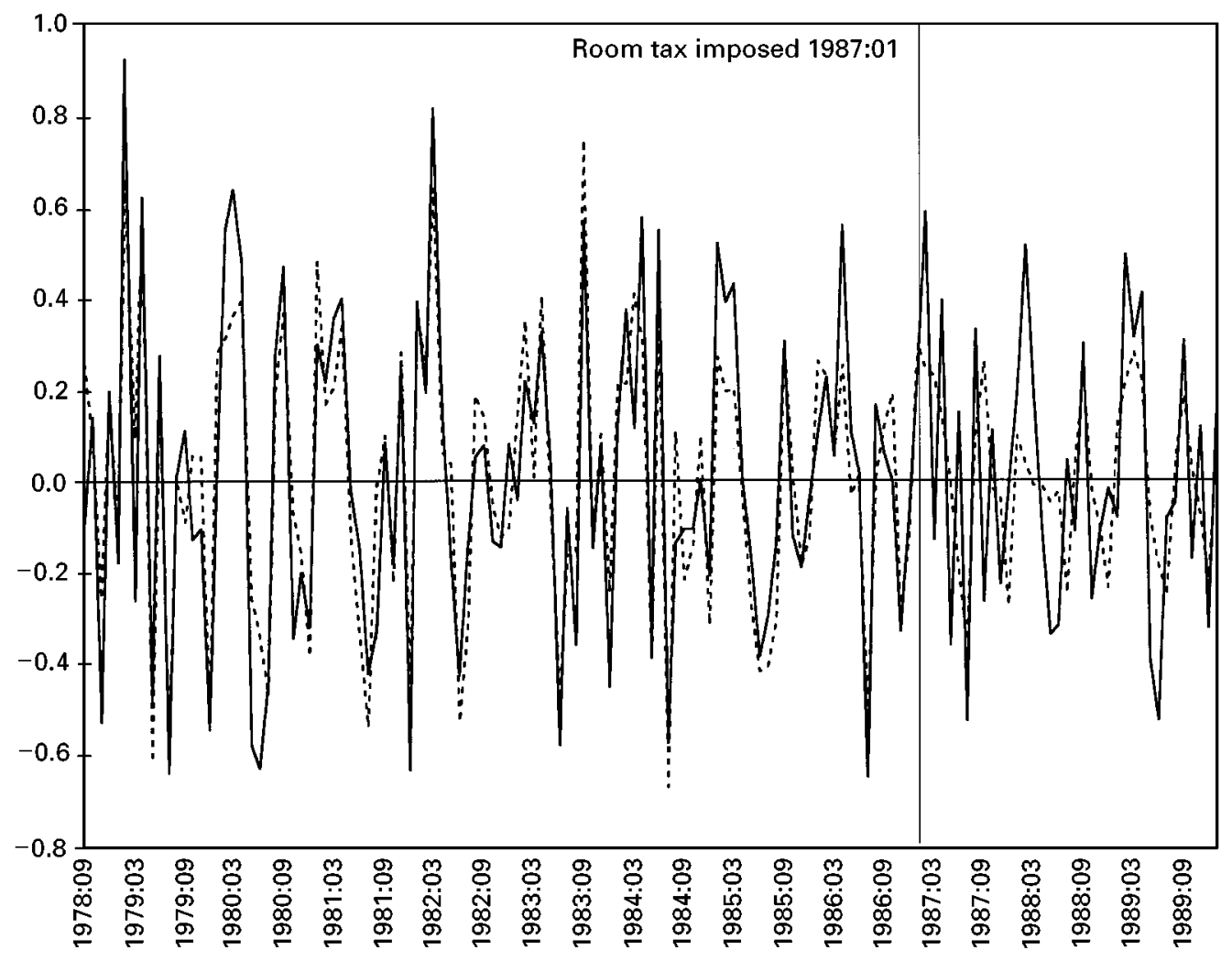

Fig. 1. Pre- and post-intervention forecasts of growth in real hotel room revenues (_ actual; ----- forecast)

fits the full-sample period almost as well as the pre-intervention period, and the residuals are found to be serially uncorrelated. ${ }^{24}$ Additional evidence of the adequacy of the selected model is presented in Fig. 2, which shows the residual errors from pre-intervention and full-sample estimation of Equation 15. ${ }^{25}$ A significant tax impact should show up as a change in the residual pattern with persistent negative residuals immediately following the tax change. These negative errors should gradually be eliminated if the tax does not permanently lower the growth of hotel revenues. Again, there appears to be no systematic behaviour left unexplained by the pre-intervention model.

While the out-of-sample fit and visual evidence presented so far is compelling, we proceed to estimate an intervention model over the full sample in an attempt to model any impact on hotel revenues of the tax imposition. As discussed by Box and Tiao (1975) and Harvey (1989), it is necessary to postulate both the form the intervention dummy should take and the shape of its transfer function. Because the room tax represents a permanent increase in hotel costs, we anticipate that it would most plausibly cause a one-time drop in the level of hotel room revenues, without changing their trend rate of growth. The growth rate time series should then experience a (series of) temporary decline(s) but then return to the path given by the pre-intervention model. This hypothesized transient effect on growth rates calls for use of a 'pulse' dummy variable that takes the value one when the tax is adopted (1987:1) and is zero in all other time periods. Following this event, there may be a delay before higher prices reduce the demand for rooms or hoteliers begin to absorb part of the room tax as lower revenues. After the impact effect, we anticipate a gradual return to trend growth rates over a number of months. We therefore add an intervention term, $\frac{w^{\prime}(B)}{1-\delta^{\prime} B} T D_{t^{-} b_{T D}}$, to Equation 15. The numerator of this transfer function captures the (possibly lagged)

\footnotetext{
${ }^{24}$ Since any systematiceffect of the intervention would be overwhelmed by the stochastic properties of the full set of residuals, we examined the correllogram and Ljung-Box $Q$-statistics using only the residuals in the period immediately following the intervention, $1987: 1$ to 1988:12.

${ }^{25}$ The residuals from a full-sample estimation of Equation 15 are shown for the post-intervention sample from 1987:1 to 1990:1, while the pre-intervention residuals are plotted for the period from 1978:9 to 1986:12.
} 
Table 4. Transfer function parameter estimates for the full sample, 1978:9-1990:1

\begin{tabular}{|c|c|c|c|}
\hline$\Delta H R_{t}=\alpha_{1}$ & $\alpha_{2} z_{2, t-1}$ & $\frac{w_{j}(B)}{\delta_{j}(B)} \Delta x_{j, t^{-} b}$ & $\frac{\theta(B)}{\phi(B)} a_{t} \quad$ (15) \\
\hline & $\begin{array}{l}\text { Input } \\
\text { variable }\end{array}$ & Estimate & $\begin{array}{l}\text { Marginal } \\
\text { significance } \\
\text { level }\end{array}$ \\
\hline$z_{1, t^{-1}}$ & $\alpha_{1}$ & 0.0726 & 0.0000 \\
\hline$z_{2, t-1}$ & $\alpha_{2}$ & -0.2101 & 0.0000 \\
\hline$C A E M P_{t}$ & $\mathrm{~W}_{1,1}$ & -11.8460 & 0.0045 \\
\hline & $\mathrm{w}_{1,2}$ & 1.3251 & 0.8184 \\
\hline & $\mathrm{w}_{1,3}$ & 6.9321 & 0.0845 \\
\hline$J P Y_{t}$ & $\mathrm{w}_{2,1}$ & -0.1100 & 0.0614 \\
\hline & $\mathrm{w}_{2,2}$ & -0.3616 & 0.0000 \\
\hline$U S W_{t}$ & $\mathrm{~W}_{3,1}$ & -0.0008 & 0.0058 \\
\hline$J P W_{t}$ & $\mathrm{w}_{4,3}$ & 0.0007 & 0.0138 \\
\hline & $\mathrm{W}_{4,4}$ & 0.0003 & 0.3539 \\
\hline & $\mathrm{W}_{4,5}$ & 0.0008 & 0.0119 \\
\hline$U S R_{t}$ & $\mathrm{~W}_{5,15}$ & -0.0049 & 0.3478 \\
\hline & $\mathrm{W}_{5,16}$ & 0.0025 & 0.6284 \\
\hline & $\mathrm{W}_{5,17}$ & -0.0123 & 0.0211 \\
\hline$a_{t}$ & $\theta_{2}$ & 0.3418 & 0.0002 \\
\hline & $\phi_{3}$ & -0.8537 & 0.0000 \\
\hline & $\phi_{9}$ & 0.2139 & 0.0056 \\
\hline $\bar{R}^{2}$ & & 0.7307 & \\
\hline $\operatorname{MSL} Q(25)$ & & 0.3237 & \\
\hline
\end{tabular}

Note: See note to Table 3.

impact effect of the tax increase, and the parameters of $w^{\prime}(B)$ are expected to be negative. The denominator term $\delta^{\prime}$ will lie between zero and one if the pulse effect on the growth rate dies out over time, as hypothesized.

Results from estimation of the intervention model are given in Table $5 .^{26}$ Two models are shown, one with a pulse dummy intervention term as described above, another using a step dummy variable, corresponding to a permanent effect on the revenue growth rate. Neither model shows a statistically significant overall impact from the room tax. Model 1 gives an impact effect of 0.2197 one month after the tax change, followed by an offsetting decline of 0.2462 in the following month. The total effect (sum of the two lag coefficients) is insignificantly different from zero at a marginal significance level of 0.964. Surprisingly, the estimated autoregressive polynomial has a root which is insignificantly different from unity indicating that any (significant) tax effect would cause a permanent change in the growth of hotel revenues. Therefore, we concentrate on the alternative Model 2 results, where a step dummy is used. Here, the impact effect is estimated to be -0.3753 two months after the tax change, followed by an offsetting increase of 0.3738 one month later. Again, the total effect is insignificantly different from zero at a marginal significance level of $99 \% .{ }^{27}$ Neither of the models presented in Table 5 suffers from serially correlated errors either over the full sample or over the two-year period immediately following the imposition of the room tax..$^{28}$

Post-intervention model performance, characteristics of the residuals, and the estimated coefficients on intervention dummy variables all support the same conclusion: there was no statistically significant impact on hotel room revenues of the room tax. Confidence intervals on our estimates would permit large negative impacts or even small positive effects, but provide no clear evidence that the tax had the substantial negative impact that hoteliers feared.

\section{CONCLUSIONS}

Taxes on hotel rooms have become a popular tax instrument for many states and localities. They are seen as a ready and politically palatable source of revenue by proponents, but as a significant tax burden by the hotel industry. In this paper, we use intervention analysis to evaluate the impact on hotel room revenues of a room levy imposed by the state of Hawaii in 1987. We find no statistically significant impact of the room tax on room revenues.

We analyse the ex post effect of the room tax on revenues within a time series econometric framework. We first model the empirical behaviour of hotel room revenues using a variant of the multi-input transfer function methodology developed by Box and Jenkins (Box, Jenkins and Reinsel, 1994). Our approach extends the basic transfer function model to include long-run cointegrating relationships between room revenues and key explanatory variables. After a suitable pre-intervention model is identified, it is applied

\footnotetext{
${ }^{26}$ Coefficients on the other transfer function terms in Equation 15' (see Table 4) are not significantly different from the results in Table 4, and are omitted for brevity. In Model 2, the coefficient on Californian employment (lag 2) does become negative again ( -2.221 as compared to -6.662 in the pre-intervention sample) although it is still insignificantly different from zero.

${ }^{27}$ Models were estimated with a pure delay ranging from zero to two months and with both pulse and step dummy variables. Alternative models yielded differing patterns of coefficient estimates (switching sign according to the length of pure delay, for example), yet our overall conclusions are unaffected by the choice of a specific model. Each of the models using a pulse dummy indicates a permanent (insignificant) growth rate effect, while each of the models using a step dummy indicates offsetting effects across two months.

${ }^{28} \mathrm{We}$ also tested for misspecification of our intervention model using a Chow-type test based on recursive residuals for the period immediately following the room tax imposition, as suggested in Harvey (1989). Recursive residual tests were performed for the 12-, 16-, and 24-month periods following the tax imposition, and also for a full-sample estimation of the pre-intervention model with no intervention effect. In no case did the tests indicate a misspecification of the intervention.
} 


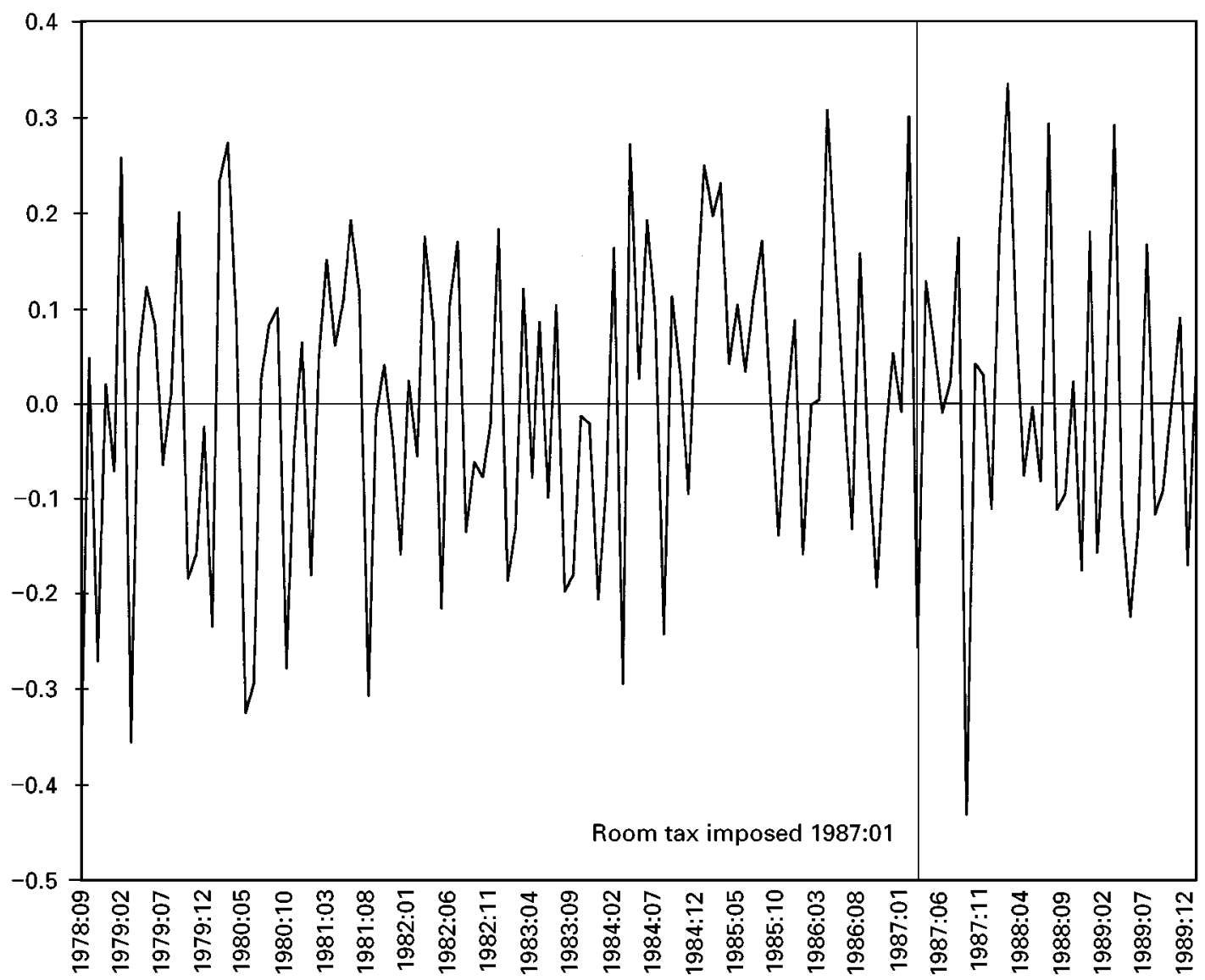

Fig. 2. Pre-intervention and full-sample residual error

Table 5. Effect of the hotel room tax: parameter estimates for intervention dummy variables

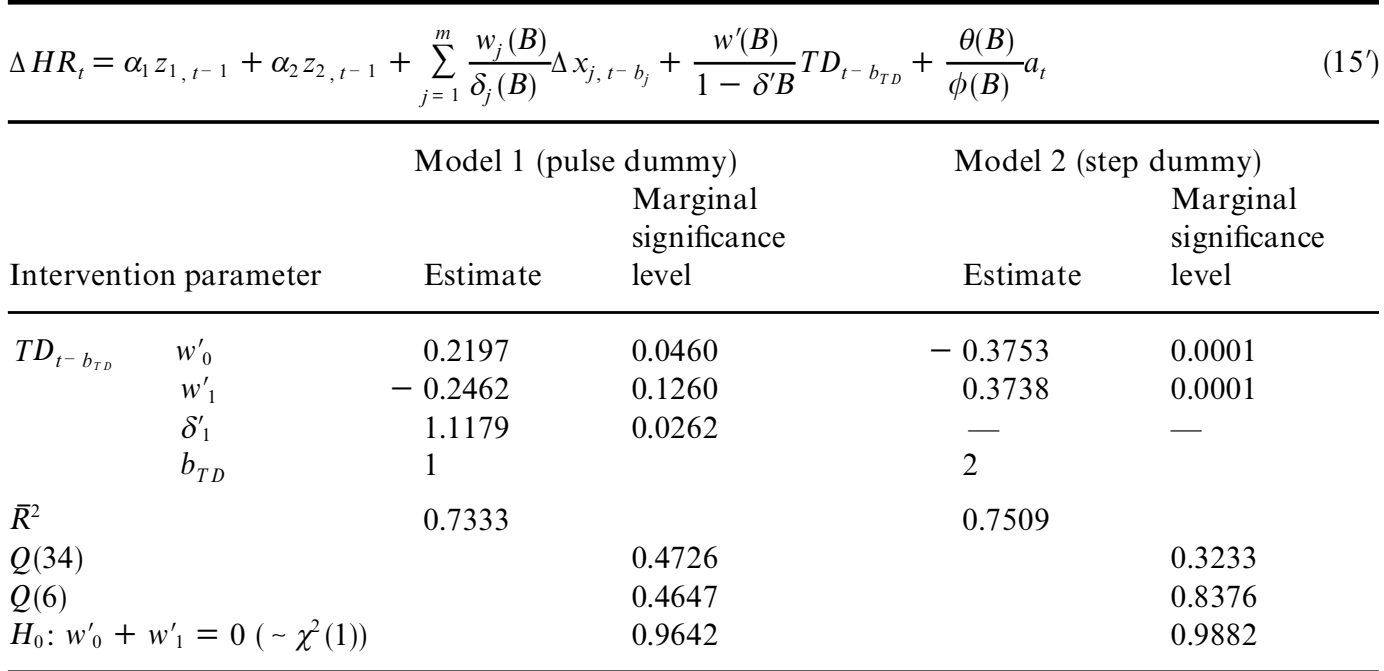

Notes: See notes for Table 3. Parameters on other transfer functions in Equation 15' are not substantially different from those in Table 4 and are omitted here; details are available from the authors upon request. $Q(34)$ is a Ljung-Box (1978) test for serially correlated residuals using the full sample. $Q(6)$ tests are for serially correlated errors using the first six autocorrelations for the two-year period immediately following the tax imposition. 
to the post-intervention sample. The model fits the postintervention period very well, and examination of the postintervention residuals reveals no systematic error that could be attributed to the tax imposition. The sum of coefficients on tax dummy variables is insignificantly different from zero. Our model appears to provide strong evidence against any significant permanent effect of the room tax on either the level or growth rate of after-tax hotel room revenues.

Our finding of insignificant room tax effects may not be too surprising. As pointed out by Bonham et al. (1992), a 5\% increase in room rates represents less than $1.5 \%$ of the total cost of a typical Hawaiian vacation, so that large adjustments to room demand are unlikely. Since the tax is added to room bills on checkout, it may not be visible to the tourist when planning a vacation. And Hawaii was not alone in implementing or increasing room taxes during this time period. To the extent that taxes were rising in competing markets, the adverse effect of Hawaii's tax on competitiveness would be reduced. Finally, we should note that our failure to find a reduction in net room revenues does not preclude adverse effects on other segments of the tourism industry. If guests substitute higher room expenditures for meals or gifts, the total impact of the tax may not be as benign as our results suggest.

The time series revenue model developed here is a useful tool for evaluating policy changes. Its apparent robustness over our decade-long sample suggests it may also be useful for forecasting and for scenario analysis. In the case of Hawaii, the model might be used to study the recent sharp downturn in Hawaiian tourism and to forecast recovery. Similar models could be developed for studying the impacts of other policy changes and programmes, for example to evaluate the impact of tourism marketing programmes or the effect on the visitor industry of sharp changes in exchange rate regimes.

\section{ACKNOWLEDGEMENTS}

An earlier version of this paper was presented at the Western Economic Association International Conference, Vancouver, BC, July 1994. We thank Jim Mak, Jack Suyderhoud and conference participants for helpful suggestions. This research was begun while we held research appointments with the Social Science Research Institute, University of Hawaii at Manoa.

\section{REFERENCES}

Armington, P. S. (1969) A theory of demand for products distinguished by place of production, International Monetary Fund Staff Papers, March, 159-76.

Beaulieu, J. J. and Miron, J. A. (1993) Seasonal unit roots in aggregate U.S. data, Journal of Econometrics, 55, 305-28.
Bonham, C., Fujii, E., Im, I. and Mak, J. (1992) Impact of the hotel room tax: an interrupted time series approach, National Tax Journal, 45, 433-41.

Box, G. E. P., Jenkins, G. M. and Reinsel, G. C. (1994) Time Series Analysis: Forecasting and Control, 3d ed., Prentice-Hall, Englewood Cliffs, NJ.

Box, G. E. P. and Tiao, G. C. (1975) Intervention analysis with applications to economic and environmental problems, Journal of the American Statistical Association, 70, 70-79.

Campbell, J. Y. and Perron, P. (1991) Pitfalls and opportunities: what macroeconomists should know about unit roots, NBER Macroeconomics Annual 1991, ed. O. J. Blanchard and S. Fischer, MIT Press, Cambridge, MA.

Canova, F. and Hansen, B. E. (1993) Are seasonal patterns constant over time? A test for seasonal stability, revised working paper, Brown University, European University Institute, and University of Rochester.

Combs, J. P. and Elledge, B. (1979) Effects of a room tax on resort hotels/motels, National Tax Journal, 32, 201-7.

Dickey, D. A., Hasza, D. P. and Fuller, W. A. (1984) Testing for unit roots in seasonal time series, Journal of the American Statistical Association, 79, 355-67. Reprinted in Hylleberg (1992).

Edlund, P.-O. (1984) Identification of the multi-input Box-Jenkins transfer function model, Journal of Forecasting, 3, 297-308.

Engle, R. F., Granger, C. W. J. and Hallman, J. J. (1989) Merging short-and long-run forecasts: an application of seasonal cointegration to monthly electricity sales forecasting, Journal of Econometrics, 40, 45-62. Reprinted in Hylleberg (1992).

Engle, R. F., Granger, C. W. J., Hylleberg, S. and Lee, H. S. (1993) Seasonal cointegration: The Japanese consumption function, Journal of Econometrics, 55, 275-98.

Fomby, T. and Hayes, K. (1990) An intervention analysis of the war on poverty, Journal of Econometrics, 43, 197-212.

Fujii, E., Im, E. I. and Sakai, M. (1993) A note on the impact of changes in ad valorem tax rates on the net revenue of firms: an application to the hotel room tax, mimeo, University of Hawaii Department of Economics.

Fujii, E., Khaled, M. and Mak, J. (1985) The exportability of hotel occupancy and other tourist taxes, National Tax Journal, 38, 169-177.

Fujii, E., Khaled, M. and Mak, J. (1988) The incidence and exportability of hotel room taxes: some further estimates, University of Hawaii at Manoa Working Paper no. 88-9.

Ghysels, E. S., Lee, H. and Noh, J. (1994) Testing for unit roots in seasonal time series: some theoretical extensions and Monte Carlo investigation, Journal of Econometrics, 62, 415-42.

Gilbert, C. L. (1990) Professor Hendry's Econometric methodology, in Modelling Economic Series, Advanced Texts in Econometrics, ed. C. W. J. Granger, Oxford University Press, New York.

Gonzalo, J. (1989) Comparison of five alternative methods of estimating long-run, equilibrium relationships, Economics Department Discussion Paper 89-55, University of California at San Diego.

Hamilton, J. D. (1994) Time Series Analysis, Princeton University Press, Princeton, NJ.

Hannan, E. J. (1963) Regression for time series, in Proceedings of Symposium on Time Series Analysis, ed. M. Rosenblatt, Wiley, New York.

Harvey, A. C. (1989) Forecasting, Structural Time Series Models and the Kalman Filter, Cambridge University Press, New York.

Harvey, A. C. (1990) The Econometric Analysis of Time Series 2nd edn., MIT Press, Cambridge, MA. 
Hawaii Department of Business, Economic Development and Tourism (1991) State of Hawaii Data Book, Honolulu.

Hawaii Visitors Bureau (1993) Aloha! Visitor Statistics, Honolulu.

Hiemstra, S. and Ismail, J. (1990) Amounts and types of room taxes levied on the lodging industry, presented to the Hospitality, Lodging and Travel Research Foundation, American Hotel and Motel Association, Purdue University, West Lafayette, Indiana.

Hiemstra, S. and Ismail, J. (1992) Analysis of room taxes levied on the lodging industry, Journal of Travel Research, 31, 42-9.

The Honolulu Advertiser (1993) Isle hotel industry opposes rise in room tax for a center, March 3, C4.

Hylleberg, S. (1992) Modeling Seasonality, Oxford University Press, New York.

Hylleberg, S. (1993) Tests for seasonal unit roots: general to specific or specific to general? mimeo, Institute of Economics, University of Aarhus.

Hylleberg, S., Engle, R., Granger, C. W. J. and B. S. Yoo (1990) Seasonal integration and cointegration, Journal of Econometrics, 44, 215-38.

Johansen, S. (1988) Statistical analysis of cointegration vectors, Journal of Economic Dynamics and Control, 12, 231-54.

Johansen, S. and Juselius, K. (1990) Maximum likelihood estimation and inference on cointegration - with applications to the demand for money, Oxford Bulletin of Economics and Statistics, 52, 169-210.

Lawless, J. F. and Wang, P. (1976) A simulation study of ridge and other regression estimators, Communications in Statistics, A5, 307-23.

Ljung, G. M. and Box, G. E. P. (1978) On the measure of lack of fit in time series models, Biometrika, 67, 297-303.

Mak, J. (1988) Taxing hotel room rentals in the U.S., Journal of Travel Research, 27, 10-15.

Mak, J. and Sakai, M. (1993) State and Local government taxation of travel and tourism: theory and practice, University of Hawaii mimeo.

McPheters, L., Mann, R. and Schlagenhauf, D. (1984) Economic response to a crime deterrence program: mandatory sentencing for robbery with a firearm, Economic Inquiry, 22, 550-70.

Osterwald-Lenum, M. (1992) A note with quantiles of the asymptotic distribution of the maximum likelihood cointegration rank test statistics, Oxford Bulletin of Economics and Statistics, 54, 461-72.

Philips, L. (1983) Applied Consumption Analysis, North-Holland, Amsterdam.

Schwert, G. W. (1989) Tests for unit roots: a Monte Carlo investigation, Journal of Business and Economic Statistics, 7, 147-59.

Stone, D. and Ziemba, W. T. (1993) Land and stock prices in Japan, Journal of Economic Perspectives, 7, 149-65.

Zuraski, R. and Sanders, H. (1990) Characteristics of tourists and state taxation of tourist-related expenditures, in 1989 Proceedings of the Eighty-Second Annual Conference on Taxation, Tax Institute of American, National Tax Association, 63-9.

\section{APPENDIX: DATA SOURCES AND DEFINITIONS}

All series are non-seasonally adjusted monthly data unless otherwise indicated. Except for interest rates, natural logarithms of all series are used in the analysis.
HR: Real Hawaii hotel room revenues. Computed from nominal room tax base data, provided by the Department of Business Economic Development and Tourism (DBEDT). Deflated by the US consumer price index for all urban consumers (CPI-U), as reported in the US Department of Commerce, Bureau of Labor Statistics, CPI Detail Report, various issues. Room revenue data are computed as $\mathrm{HR}=\mathrm{TAXBASE}(\mathrm{t}+1) / \mathrm{USCPI}(\mathrm{t}) * 1.0416$, to adjust for lagged reporting and to back in the $4 \%$ general excise tax.

$J P Y$ : Japanese real disposable income. Computed from nominal disposable income in yen, deflated by the Japanese consumer price index. Both series are taken from the Japan Statistical Association, Monthly Statistics of Japan, various issues.

USY: US real personal disposable income. Computed from nominal personal disposable income (seasonally adjusted), reported in the Survey of Current Business, various issues. Deflated by the US consumer price index.

CAEMP: Californian non-farm employment, obtained from the Bureau of Labor Statistics Economic Bulletin Board.

$J P W$ : Real Japanese stock price. Tokyo stock price index in nominal terms, deflated by the Japanese consumer price index. The former is taken from Monthly Statistics of Japan; the latter is taken from Monthly Statistics of Japan and from Sorifu Tokeikyoku, Monthly Report of Retail Prices.

USW: Real US stock price. S\&P 500 common stock composite index, reported in the Survey of Current Business. Obtained in machine-readable form from the Citibank Economic Database Citibase. Deflated by the US consumer price index.

EXCH: Real yen/dollar exchange rate. Nominal yen/dollar exchange rate on a monthly average basis (series rf) is taken from International Monetary Fund, International Financial Statistics, various issues. Real exchange rate is computed by multiplying the nominal rate by the ratio of the US and Japanese consumer price indexes.

$J P R$ : Real Japanese government bond rate. Interest rate on Japanese seven-year government bonds, reported in International Monetary Fund, International Financial Statistics, various issues, minus the actual CPI inflation rate.

USR: Real US government bond rate. Interest rate on US seven-year government bonds, reported in Federal Reserve Bulletin, various issues, minus the actual CPI inflation rate.

$H W A G E$ : Real Hawaii hotel industry wages. Average nominal wage rate in Hawaii hotels (Bureau of Labor Statistics data, obtained from DBEDT), deflated by the US consumer price index. 